\title{
NOTIZEN
}

\section{The Conformations of Oxacyclooctanes}

Ulrich Burkert*

Fakultät für Chemie, Universität Konstanz, Postfach 5560, D-7750 Konstanz

Z. Naturforsch. 35 b, 1479-1481 (1980); received July 18, 1980

Molecular Mechanics, Force Field Calculations, Oxocanes, Cyclooctane,

Conformational Analysis

The geometries and energies of the conformers of oxocane, the isomeric di- and trioxocanes, and of 1,3,5,7-tetroxocane were calculated by molecular mechanics. A boat-chair conformation was preferred by all molecules. From the preference of oxygen in the boat-chair conformations of oxocane (position 3 over l over 4) the preferred boat-chair form of all other oxocanes can be derived. The results are compared to experimental data, which in part can be reinterpreted. Additional CNDO/2 and MINDO/3 calculations were performed for 1,3,5,7-tetroxocane.

Cyclooctane can adopt three conformational families, the boat-chair (BC), chair-chair (CC) and boat-boat (BB) forms, and the three methods used to elucidate the conformations of cyclooctanes, $\mathrm{X}$-ray crystallography, dynamic nuclear magnetic resonance (DNMR), and molecular mechanics calculations, indicate that in the absence of sterically hindering substituents the $\mathrm{BC}$ form is preferred [1]. Main reasons for the higher energies associated with the $\mathrm{BC}$ and $\mathrm{CC}$ forms are transannular repulsions between the hydrogens pointing into the ring, and torsional interactions. When heteroatoms with lower valency than four or $\mathrm{sp}^{2}$ hybridized carbons as in a double bond or a carbonyl group are introduced into the ring, the BB form might be expected to contribute more strongly to the conformational equilibrium, as 1,5-repulsions disappear [2]. However, at the same time the energies of the other conformations change, which are more difficult to estimate. For a quantitative analysis, the effects of oxygen atoms in the cyclooctane ring on the conformational equilibrium were therefore studied by means of molecular mechanics calculations [3] with a recently developed ether force field $[4,5]$. The calculations were performed under complete geometry optimization, employing a block-diagonal Newton-Raphson procedure without symmetry restrictions [3-5].

* Reprint requests to Dr. Ulrich Burkert.

0340-5087/80/1100-1479/\$01.00/0
Table I. Conformational energies of oxacyclooctanes (kcal mol-1).

\begin{tabular}{|c|c|c|}
\hline & & Relative energy (kcal $\mathrm{mol}^{-1}$ ) \\
\hline 1 & $\begin{array}{l}\text { BC-1 } \\
\text { BC-2 } \\
\text { BC-3 } \\
\text { BC-4 } \\
\text { BC-5 } \\
\text { Crown } \\
\text { BB-1 } \\
\text { BB-2 }\end{array}$ & $\begin{array}{l}0.41 \\
2.82 \\
0.0 \\
1.58 \\
2.62 \\
2.10 \\
3.30 \\
5.53\end{array}$ \\
\hline 2 & $\begin{array}{l}\text { BC-1,3 } \\
\text { BC-2,4 } \\
\text { BC-3,5 } \\
\text { BC-4,6 } \\
\text { Crown } \\
\text { BB-1,3 } \\
\text { BB-2,4 }\end{array}$ & $\begin{array}{l}0.0 \\
4.60 \\
3.13 \\
2.74 \\
2.40 \\
1.22 \\
8.71\end{array}$ \\
\hline $\mathbf{3}$ & $\begin{array}{l}\text { BC-1,4 } \\
\text { BC-2,5 } \\
\text { BC-3,6 } \\
\text { Crown } \\
\text { BB }\end{array}$ & $\begin{array}{l}0.58 \\
2.95 \\
0.0 \\
1.18 \\
4.45\end{array}$ \\
\hline 4 & $\begin{array}{l}\text { BC-1,5 } \\
\text { BC-2,6 } \\
\text { BC-3,7 } \\
\text { Crown } \\
\text { BB-1,5 }\end{array}$ & $\begin{array}{l}1.57 \\
2.73 \\
0.0 \\
0.72 \\
3.44\end{array}$ \\
\hline $\mathbf{5}$ & $\begin{array}{l}\text { BC-1,3,5 } \\
\text { BC-2,4,6 } \\
\text { BC-3,5,7 } \\
\text { BC-1,3,7 } \\
\text { Crown } \\
\text { BB-1,3,5 }\end{array}$ & $\begin{array}{l}2.04 \\
4.95 \\
4.89 \\
0.0 \\
3.61 \\
1.73\end{array}$ \\
\hline 6 & $\begin{array}{l}\text { BC-1,3,6 } \\
\text { BC-2,4,7 } \\
\text { BC-1,4,6 } \\
\text { Crown } \\
\text { BB }\end{array}$ & $\begin{array}{l}0.0 \\
1.94 \\
1.34 \\
1.12 \\
2.05\end{array}$ \\
\hline 7 & $\begin{array}{l}\text { BC-1,3,5,7 } \\
\text { BC-2,4,6,8 } \\
\text { Crown } \\
\text { BB }\end{array}$ & $\begin{aligned} & 0.0 \\
& 4.32 \\
& 2.77 \\
& 14.32\end{aligned}$ \\
\hline
\end{tabular}

Table I lists only the energies of stable energy minima. TCC conformations were converted into the crown form in every case studied during energy minimization. A larger number of $\mathrm{BC}$ and $\mathrm{BB}$ conformers is feasible for oxocanes than for cyclooctane, however, as nonequivalent ring positions exist where the heteroatom(s) can be placed. In cases where two BB conformations are feasible, the preferred conformer was the one with the maximum number of oxygen atoms in the mirror planes of the 
cyclooctane BB conformation (Table I). The calculated order of stability of the five BC conformers found for oxocane 1 points to the relative importance of different transannular repulsions in the parent compound, the strong repulsion between $\mathrm{C}_{3}$ and $\mathrm{C}_{7}$ (relieved in BC-3) and short contacts between the hydrogen at the 1-position pointing into the ring with those on $\mathrm{C}_{4}$ and $\mathrm{C}_{6}$ (two such repulsions relieved in BC-1, only one in BC-4) [6]. These results agree with those of preliminary molecular mechanics calculations by Anet [7]. All possible BC conforma-

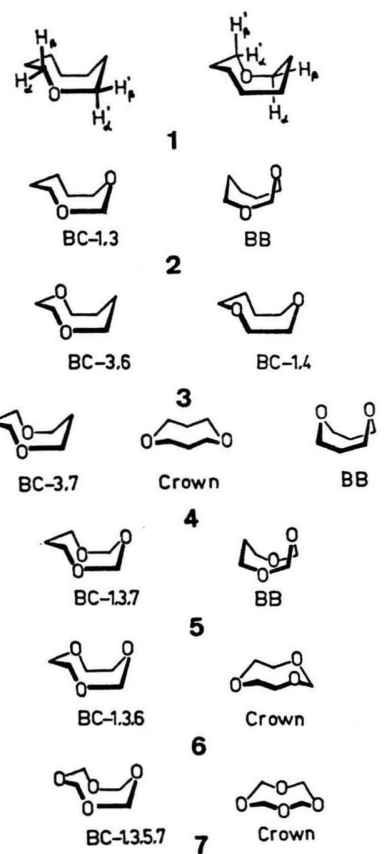

Fig. 1. Preponderant conformation of oxacyclooctanes.

tions were also found to be energy minima for compounds 2-7. Their stabilities reflect those of the $\mathrm{BC}$ conformations of $\mathbf{1}$. In the most stable BC form an oxygen atom invariably occupies the 3 -position, the location of the other oxygen atom(s) is determined by the compound's constitution (Table I and Fig. 1).

The relative energies of the (most stable) BC, crown and $\mathrm{BB}$ conformations of the oxocanes are surprisingly similar to those of the cyclooctane conformations (MM 2 force field: crown $1.2 \mathrm{kcal} \mathrm{mol}^{-1}$, BB $3.6 \mathrm{kcalmol}^{-1}$ less stable than BC [8]). The BC conformation is preferred in every case (Table I), only the relative stabilities of the $\mathrm{BB}$ and crown forms were found to be different. The BB form of 1,3-dioxocane 2 is favored over the crown as two strong transannular repulsions are relieved. Electro- static interactions reduce this preference for the BB form in 1,3,5-trioxocane 5 and let the crown form of $1,3,5,7$-tetroxocane 7 be preferred over BB. The higher stability of the $\mathrm{BC}$ form of 7 also was found in recent molecular mechanics calculations by Allinger with a force field using dipole interactions instead of the charge interactions used here for the electrostatics [9]. For the crown forms of 1,4-dioxocane (3) and 1,3,6-trioxocane (6) remarkably low energies were obtained because repulsions on the upper and lower side of the crown are relieved.

Experimental data are available concerning the conformations of $\mathbf{1}, \mathbf{2}, \mathbf{6}$, and 7; compounds 3-5 are not known at present. For 2, the BC-1,3 has been shown to exist in solution [7]. Low temperature NMR data could not decide between a BC conformation with permanent $\mathrm{C}_{\mathrm{s}}$ symmetry (BC-1) and unsymmetrical, but repidly pseudorotating $\mathrm{BC}$ forms as the BC-3 form favored by the calculations [10]. Discrepancies with experimental data seem to exist for compounds 6 and 7 , as NMR data have indicated that the $\mathrm{BC}$ and crown conformations of 6 are isoenergetic and that the crown form of 7 prevails over $\mathrm{BC}[2,10]$. However, this appears to be caused by medium effects, the more polar form (crown) being favored in polar solutions. Thus, the conformational equilibrium of $\mathbf{7}$ has been shown to depend strongly on solvent and concentration (at high concentrations the polar solute increases the polarity of the solution), with prevailance of the crown form in more polar solvents and at higher concentrations [11]. In the gas phase, the $\mathrm{BC}$ form predominates [11]. In the crystal the crown form of 7 has been found, stabilized extremely well by intermolecular interactions (exp. and, in brackets, calcd. bond lengths and angles : $r_{\mathrm{CO}}=140.3$ $(140.5) \mathrm{pm}, \theta_{\mathrm{OCO}}=113.8 \quad(114.1)^{\circ}, \theta_{\mathrm{COC}}=116.6$ $\left.(112.5)^{\circ}\right)$ [12]: The rings are packed in continuous stacks, where the ring dipole moments (perpendicular to the ring plane) are parallel. The dipole moments of neighboring stacks point in opposite directions [12].

For 7, the preference for the same BC conformation was found in $\mathrm{CNDO} / 2$ calculations with the optimized molecular mechanics geometries (crown: $7.22 \mathrm{kcal} \mathrm{mol}^{-1}$, BC-2,4,6,8 $11.10 \mathrm{kcalmol}^{-1}$ less stable). Geometry optimization with the MINDO/3 method gave unsatisfactory bond lengths and angles (crown conformation: $r_{\mathrm{CC}}=135.4 \mathrm{pm}, \theta_{\mathrm{OCO}}=123.2^{\circ}$, $\theta_{\mathrm{COC}}=134.7^{\circ}$ ) with lead to a very unusual BC conformation with atoms $2-4$ and 6-8 nearly coplanar. This explains why the $\mathrm{BC}$ form was falsely calculated to be less stable than the crown form by $18.7 \mathrm{kcalmol}^{-1}$ with this method.

The author is indebted to Professor N. L. Allinger for a preprint on related work [9]. 
[1] For reviews see F. A. L. Anet, Topics in Current Chemistry 45, 169 (1974), F. A. L. Anet and R. Anet in L. M. Jackman and F. A. Cotton (eds.): Dynamic Nuclear Magnetic Resonance Spectroscopy, p. 543, Acad. Press, New York 1975.

[2] J. Dale, T. Ekeland, and J. Krane, J. Am. Chem. Soc. 94, 1389 (1972).

[3] N. L. Allinger, Adv. Phys. Org. Chem. 13, 1 (1976).

[4] U. Burkert, Tetrahedron 33, 2237 (1977).

[5] U. Burkert, Tetrahedron 35, 1945 (1979).

[6] For cyclooctanone a slightly different stability order, with the BC-4 form as second most stable, and BC-1 third most stable, has been calculated.
N. L. Allinger, M. T. Tribble, and M. A. Miller, Tetrahedron 28, 1173 (1972).

[7] F. A. L. Anet, P. J. Degen, and J. Krane, J. Am. Chem. Soc. 98, 2059 (1096).

[8] N. L. Allinger, J. Am. Chem. Soc. 99, 8127 (1977) and personal communication.

[9] N. L. Allinger, S. H.-M. Chung, D. H. Glaser, and H. Hönig, Israel J. Chem. 20, 51 (1980).

[10] F. A. L. Anet and P. J. Degen, J. Am. Chem. Soc. 94, 1390 (1972).

[11] M. Kobayashi and S. Kawabata, Spectrochim. Acta 33 A, 549 (1977).

[12] Y. Chatani, T. Yamauchi, and Y. Miyake, Bull. Chem. Soc. Jpn. 47, 583 (1974). 